\title{
Correction Notice: Impact of brass contents on thermal, friction and wear properties of brake linings composites
}

Amira Sellami ${ }^{1,}$, Mohamed Kchaou ${ }^{1}$, Reçai Kus ${ }^{2}$, Jamal Fajoui ${ }^{3}$, Riadh Elleuch ${ }^{1}$, and Frédéric Jacquemin ${ }^{3}$

${ }^{1}$ University Sfax, LASEM, National Engineering School of Sfax, B.P. W3038, Sfax, Tunisia

${ }^{2}$ Selcuk University, Technology Faculty Konya, Turkey

${ }^{3}$ Research Institute in Civil and Mechanical Engineering (GeM) (UMR,CNRS 6183), 58 street Michel Ange, BP 420, 44606 Saint-Nazaire Cedex, France

Received: 4 December 2018 / Accepted: 4 December 2018

The online version of the original article can be found under: Mechanics \& Industry 19, 105 (2018) https://doi.org/10.1051/meca/2016083

The name of the last author is corrected to Frédéric Jacquemin. The publishers apologize for the inconvenience.

* e-mail: amira_sellami@hotmail.com 